\title{
MERCADO LABORAL: LECCIONES DEL ESTADO DE BIENESTAR ALEMÁN*
}

\author{
Hans-Werner Sinn
}

\begin{abstract}
Alemania tiene una amplia experiencia en subsidios que afectan el empleo, como los que discute actualmente en Chile el Consejo Asesor Presidencial de Trabajo y Equidad. Existe, entonces, la oportunidad de apreciar cuáles iniciativas han dado resultado y cuáles no. En estas páginas se sostiene que para construir una sociedad moderna se necesita un Estado benefactor. Sin embargo, si el ingreso mínimo es generoso, se comprime la distribución salarial desde abajo y habrá una considerable tasa de desempleo entre los trabajadores no calificados. La prueba más clara al respecto es el enorme desempleo en Alemania Oriental después de la unificación. Para conciliar la meta ética de asegurar empleo con la meta de asegurar ingreso, se requiere que el Estado benefactor ofrezca un ingreso mínimo mayor a quien trabaja que a quien permanece inactivo.
\end{abstract}

Hans-Werner Sinn. Presidente del Instituto Ifo, Munich, Alemania. Profesor titular de finanzas públicas y director del Centro de Estudios Económicos (CES) en la Universidad Ludwig-Maximilians de Munich, Alemania.

* Ésta es una transcripción de la conferencia dictada en el Centro de Estudios Públicos el 2 de enero de 2008. También fue presentada al Consejo Asesor Presidencial de Trabajo y Equidad, presidido por Patricio Meller. Estudios Públicos agradece la traducción de Alberto Ide y la edición de Salvador Valdés.

Estudios Públicos, 109 (verano 2008). 


\section{Cómo es un verdadero Estado "benefactor”}

$\mathrm{E}$ xisten varias razones que justifican la creación de un Estado benefactor. Conviene declararlas en esta introducción para dejar en claro que las críticas contenidas en este trabajo, que conducen a las reformas propuestas, no tienen el ánimo de desmantelar el Estado benefactor*.

Entendemos el Estado benefactor como el conjunto de aquellos programas estatales que buscan eliminar la pobreza extrema y reducir el grado de desigualdad de ingreso.

La primera justificación para un Estado benefactor es que colabora a sostener la paz social. En la medida en que los menos afortunados en bienes materiales reciban ayuda del resto de la sociedad, tendrán mayor interés en preservar la sociedad y serán más proclives a rechazar los intentos de destrucción y refundación que pongan en peligro la paz, que es el principal bien público.

Un segundo beneficio es de carácter individual: se espera una menor tasa de delincuencia en una sociedad donde opera un Estado de bienestar. En mi ciudad, Munich, una mujer puede pasear por toda la ciudad durante la noche sin riesgo de ser asaltada o molestada.

El tercer beneficio es que otorga a todos la tranquilidad material básica que permite participar en política, impidiendo que esta actividad quede limitada a la elite económica. Este beneficio es más valioso para las democracias que para otras formas de organización política.

También hay dos beneficios económicos, de carácter estrictamente material. Primero, un Estado de bienestar manifiesta de manera tangible la solidaridad entre los integrantes de una nación. Un genuino interés en el bienestar de los conciudadanos incluye el asegurar grados suficientes de igualdad material. Segundo, y creo de gran importancia para el crecimiento económico de largo plazo, un Estado de bienestar provee un seguro contra los malos resultados en los emprendimientos. Este atributo del Estado de bienestar fomenta la toma de riesgo empresarial y, por tanto, acelera el crecimiento económico.

Sin embargo, el Estado de bienestar siempre trae consigo un costo económico: genera desincentivos para ingresar y permanecer en el mercado laboral. Este punto será analizado en detalle en este trabajo.

¿Qué tamaño debe tener un Estado de bienestar? Algunos antecedentes empíricos son ilustrativos. Los Cuadros $\mathrm{N}^{\circ} 1$ y $\mathrm{N}^{\circ} 2$ revelan que Alemania ha creado un Estado benefactor maduro y desarrollado. Su construcción se inició en la década de 1880, hace ya más de 120 años, en la

* Nota del editor: en este trabajo se usan indistintamente las expresiones "Estado benefactor" y "Estado de bienestar". 
CUADRO No $1: \quad$ MERCADO LABORAL EN CHILE Y ALEMANIA

\begin{tabular}{lcc}
\hline & Chile & Alemania \\
\hline $\begin{array}{l}\text { Empleo por cuenta propia } \\
\text { (\% del empleo total) }\end{array}$ & $25 \%$ & $11 \%$ \\
$\begin{array}{l}\text { Desigualdad del ingreso } \\
\text { (coeficiente de Gini) }\end{array}$ & 0,55 & 0,34 \\
$\begin{array}{l}\text { Tamaño del Estado de bienestar } \\
\text { (transferencias sociales: salud, educación, pobreza } \\
\text { en la vejez, como \% del PIB) }\end{array}$ & $15 \%$ & $31 \%$ \\
\hline
\end{tabular}

Fuente: Instituto Ifo.

CUADRO N ${ }^{\circ}$ 2: $\quad$ GRADO DE APOYO ESTATAL AL INGRESO MONETARIO DE LOS POBRES EN CHILE Y ALEMANIA

(\% del ingreso cuya fuente son transferencias del Estado)

\begin{tabular}{lcc}
\hline & Chile & Alemania \\
\hline $1^{\text {er }}$ decil $(10 \%+$ pobre $)$ & 26 & 98 \\
$2^{\circ}$ decil (segundo $10 \%+$ pobre $)$ & 8 & 81 \\
$3^{\text {er }}$ decil (tercer $10 \%+$ pobre) & 5 & 66 \\
\hline
\end{tabular}

Fuente: Instituto Ifo.

época del Canciller von Bismarck. Ha evolucionado con el tiempo, hasta el punto en que ahora nos encontramos con un país que ha sido completamente transformado por el Estado benefactor.

El Cuadro $\mathrm{N}^{\circ} 2$ muestra que en Chile el tercer decil de personas ordenadas por ingreso obtiene sólo el 5\% de su ingreso total en la forma de subsidios monetarios del Estado. En cambio, en Alemania y el grueso de Europa continental la cifra análoga para el tercer decil supera el 60\%.

Otra cifra que revela los alcances del Estado de bienestar alemán es el $42 \%$ de la población adulta que recibe al menos la mitad de su ingreso monetario de transferencias estatales (principalmente pensiones públicas, pero también subsidios de desempleo, pensiones por jubilación anticipada, asignaciones de matrícula para estudiantes y asignaciones a los estudiantes para financiar su subsistencia).

En Alemania oriental, donde escasean los empleos, este porcentaje es mayor: el $47 \%$ de la población adulta recibe al menos la mitad de su ingreso de subsidios del Estado. Esta cifra ayuda a comprender por qué el ex Partido Comunista de Alemania Oriental, actual Partido del Socialismo 
Democrático (Partei des Demokratischen Sozialismus, PDS), está disputando codo a codo con la Democracia Cristiana el primer lugar entre los partidos en Alemania oriental.

\section{El Estado benefactor como competidor}

El Estado de bienestar alemán paga un ingreso de "reemplazo", cuyo objetivo es sustituir el ingreso laboral cuando éste desaparece. La persona recibe el subsidio cuando no tiene un empleo remunerado, y deja de recibir el subsidio desde el momento en que percibe un ingreso laboral. Como vemos, la lógica del seguro justifica esta práctica, que parece natural. Sin embargo, veremos también que otra consecuencia de ella es que el Estado actúa como competidor de las empresas privadas en el mercado laboral.

Para empezar, Alemania cuenta con planes generosos de jubilación anticipada: con 58 años de edad se puede recibir una pensión muy cercana al monto total del salario neto de actividad. Aun cuando la edad normal de jubilación es 65 años, si uno se retira antes se aplica una pequeña deducción. La condición para recibir esta generosa jubilación estatal es, como se explicó, que no se trabaje en forma remunerada al mismo tiempo que se reciba la pensión.

Además Alemania cuenta con un sistema de subsidio de cesantía de dos niveles, el cual fue reformado en una dirección razonable durante el gobierno del Canciller Gerhard Schröder (1998-2005). En el primer nivel, el beneficiario (cesante) recibe entre un $60 \%$ y un $67 \%$ de su sueldo anterior por un período de hasta 18 meses (antes de las reformas de Schröder este plazo era de 32 meses, y para personas menores de cierta edad actualmente el plazo es de 12 meses, aunque en algunos casos puede ser superior).

En el segundo nivel, que se aplica una vez vencida la duración del subsidio de primer nivel, existe otro subsidio de cesantía que es una suma uniforme, denominada "salario mínimo de subsistencia" (también es la suma entregada a los inválidos). Esta suma, garantizada por el Estado, no tiene límite de duración (por supuesto, dura hasta ser reemplazada por una pensión de vejez o invalidez igualmente generosa). La reforma de Schröder en este punto terminó con la proporcionalidad entre el monto de este subsidio y el salario promedio que el beneficiario (cesante) tuvo en el período previo a la cesantía.

Lo importante son los niveles de estos subsidios. Después de la reforma de Schröder, el "salario mínimo de subsistencia” para una persona soltera quedó en US\$ 1.000 mensuales, y para una familia con dos hijos, en 
US\$ 2.300 mensuales $^{1}$. Se trata de un ingreso neto disponible para gastos, pues no incluye el valor del seguro de salud, que se entrega por separado. Si incluimos el valor del seguro de salud, una familia de cuatro personas obtiene alrededor de US\$ 3.000 al mes, descontados los impuestos. Estamos, por tanto, hablando de cantidades considerables, suficientes para subsistir con cierta holgura.

¿Qué efectos tiene este programa sobre el mercado laboral? El Estado benefactor, tal como ha sido estructurado en Alemania, actúa como competidor de las empresas privadas en el mercado laboral, pues asigna fondos a condición de que el beneficiario no trabaje a cambio de una remuneración. El Estado retira gente del mercado laboral para integrarla al sector público, pero no como funcionario pagado, sino como un receptor de dinero que está impedido de trabajar en forma remunerada, pues si lo hace pierde el subsidio.

Por cierto que si recibimos ese monto de dinero del Estado sin trabajar, sólo aceptaremos un empleo en el sector privado si con él ganamos una suma superior al subsidio. De lo anterior surge indirectamente, pero con gran fuerza, una exigencia de salario mínimo. A diferencia de Chile y de otros países, Alemania no ha tenido un salario mínimo legal hasta ahora. En Estados Unidos el salario mínimo legal a nivel nacional es de 4,0 euros por hora, es decir alrededor de US\$ 5,50 por hora. Está prohibido trabajar a cambio de una remuneración inferior a eso. Si bien en Alemania no existe un salario mínimo legal, sí se ha creado un salario mínimo implícito, que se desprende del monto que el Estado entrega a los cesantes bajo la condición de que no trabajen en forma remunerada.

El ciudadano común enfrenta la siguiente situación: hay dos agentes que le ofrecen dinero. Ambos le ofrecen una suma de dinero similar. Uno es el empresario privado, el capitalista, que le ofrece dinero a cambio de su trabajo. El otro es el funcionario de asistencia social, que le ofrece dinero a cambio de que no trabaje remuneradamente. Desde luego, es imposible aceptar ambas ofertas a la vez.

El ciudadano común no sabe cuál oferta aceptar. A menudo se inclina por la asistencia social, pues el empresario sólo puede pagar un salario que guarde proporción con la productividad del individuo. El empresario no es altruista y su objetivo es ganar dinero empleando a esta persona. Por ello, el máximo monto de dinero que está dispuesto a pagar dependerá de cuán productiva sea la persona. Si el empresario le pagara una suma superior a su productividad, entonces perdería dinero, por lo que evitará hacerlo. Por este motivo, si el funcionario de asistencia social ofrece un monto supe-

\footnotetext{
${ }^{1}$ Se utilizó el tipo de cambio vigente en 2006, del orden de 1,33 a 1,40 dólares de Estados Unidos por euro.
} 
rior a la productividad del beneficiario, entonces no habrá manera de emplear a esta persona en el sector privado.

$\mathrm{O}$, para plantearlo en otras palabras, el empleado desea que su salario en el sector privado sea superior al salario de reemplazo que le paga el Estado. Al mismo tiempo, el empleador desea que el salario sea inferior a la productividad de ese trabajador. Como resultado de ambas desigualdades, no existen empleos para aquellos ciudadanos cuya productividad laboral es inferior al salario de reemplazo ofrecido por el Estado. Estas desigualdades explican lo que ocurre en el mercado laboral alemán respecto de los trabajadores de menor productividad: el subsidio de cesantía alemán es un destructor de empleos.

El Grafico $\mathrm{N}^{0} 1$ muestra el tamaño del salario mínimo legal en algunos países, en relación con el tamaño del salario mediano de los ocupados. El salario mediano es aquel donde la mitad de los ocupados recibe un salario mayor y la otra mitad recibe un salario menor*.

\section{GRÁFICO No ${ }^{\circ}$ : $\quad$ SALARIO MÍNIMO EN RELACIÓN CON EL SALARIO MEDIANO}

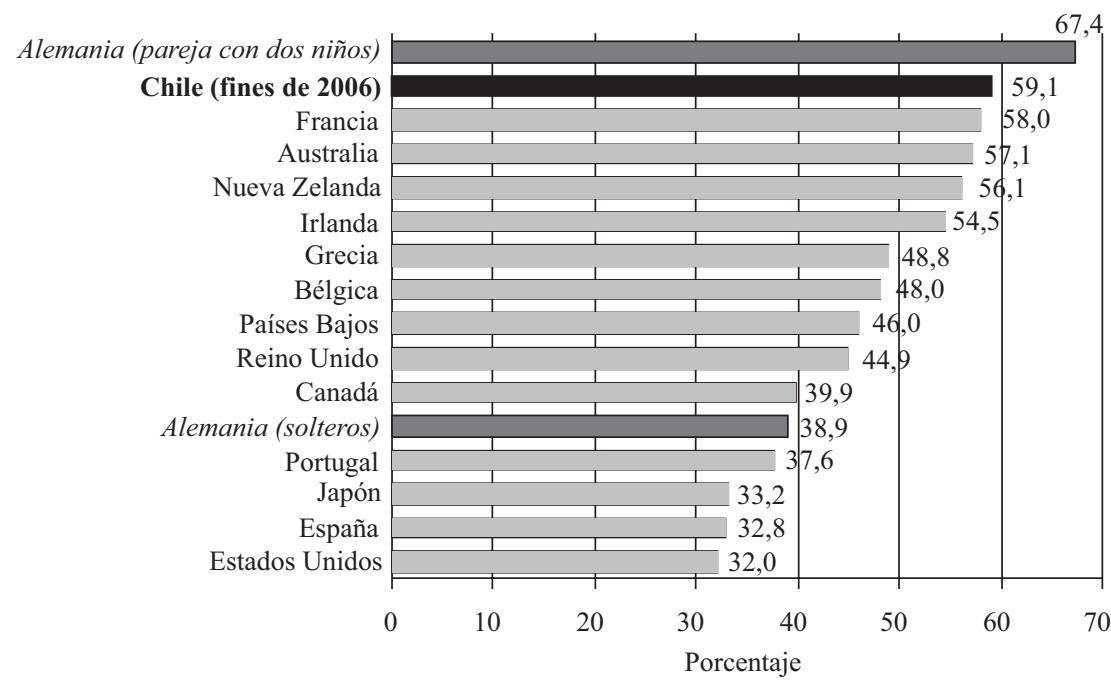

Fuente: Cálculos del Instituto Ifo.

* Nota del editor: La presencia de un salario mínimo legal o de un subsidio de cesantía de subsistencia excluye del conjunto de los ocupados a las personas de menor productividad, y por lo tanto el salario mediano de los ocupados que van quedando crece a medida que aumenta el monto del salario mínimo legal. En cambio, el salario mediano de la fuerza de trabajo, que incluye a los desempleados, es una cifra independiente del monto del salario mínimo legal, que sólo depende de la productividad laboral. 
Estados Unidos se ubica en el extremo inferior de la escala, como se aprecia en el Gráfico $\mathrm{N}^{\circ} 1$, con un salario mínimo legal que representa apenas el 32\% del salario mediano. También están graficados los dos salarios mínimos implícitos de Alemania (no tenemos niveles oficiales), que se desprenden de dos ingresos mínimos de subsistencia, uno para solteros y otro para parejas con dos hijos en que uno de los adultos trabaja en casa. La cifra correspondiente a las personas solteras en Alemania, de 38,9\%, no es alta en comparación con otros países, pero la correspondiente a una persona casada y con dos hijos sí lo es. En Chile la cifra para solteros es 59,1\%, considerablemente superior a la de Alemania en el caso de solteros.

\section{El malestar alemán}

El ingreso de reemplazo garantizado por el Estado de bienestar en Alemania se ha vuelto más generoso con el paso del tiempo en términos absolutos. El Gráfico No 2 revela que, además, el Estado de bienestar alemán tiende a ofrecer beneficios cada vez mayores en relación con la productividad laboral ${ }^{2}$. En efecto, según el gráfico, entre 1970 y 2004 el salario mínimo implícito subió $25 \%$ en relación con el salario líquido promedio de los ocupados. $\begin{array}{ll}\text { GRÁFICO No 2: } & \text { AUMENTO ACUMULADO EN ALEMANIA DEL SALARIO LÍQUIDO Y DEL } \\ & \text { SUBSIDIO DE DESEMPLEO (1970-2004) }\end{array}$

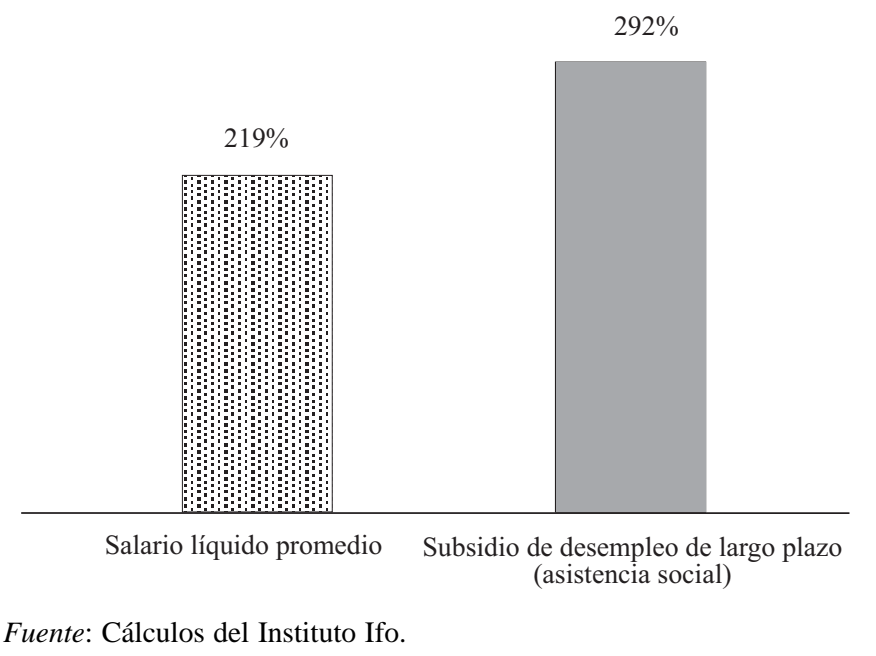

\footnotetext{
${ }^{2}$ Esta cifra no considera el efecto de la reforma de Schröder, ocurrida en 2005.
} 
Así pues, el Estado de bienestar ha sido cada vez más poderoso en el mercado laboral alemán. Y la consecuencia es claramente perceptible.

En el Gráfico $N^{\circ} 3$ se aprecian las tasas de desempleo para distintos niveles educacionales entre 1975 y 2005. No se observan grandes variaciones entre las personas con título universitario, pero entre aquellas que han completado programas de capacitación técnica la tasa de desempleo casi se duplicó durante ese período, aunque sólo llegó a 7,4\% en 2005. Pero la situación para los trabajadores no calificados - que carecen de capacitación técnica- fue muy diferente, pues su tasa de desempleo aumentó en cerca de 18 puntos porcentuales durante esas tres décadas.

El Gráfico $N^{\circ} 4$ muestra que la distorsión del empleo para los trabajadores menos calificados es mucho mayor en Alemania que en otros países de la OCDE.

He aquí el problema alemán: la tasa de desempleo enormemente alta entre los trabajadores no calificados, es decir con educación inferior a se-

GRÁFICO No 3: TASAS DE DESEMPLEO POR NIVEL EDUCACIONAL EN ALEMANIA OCCIDENTAL Y BERLÍN OCCIDENTAL ${ }^{1}:$ 1975-2005

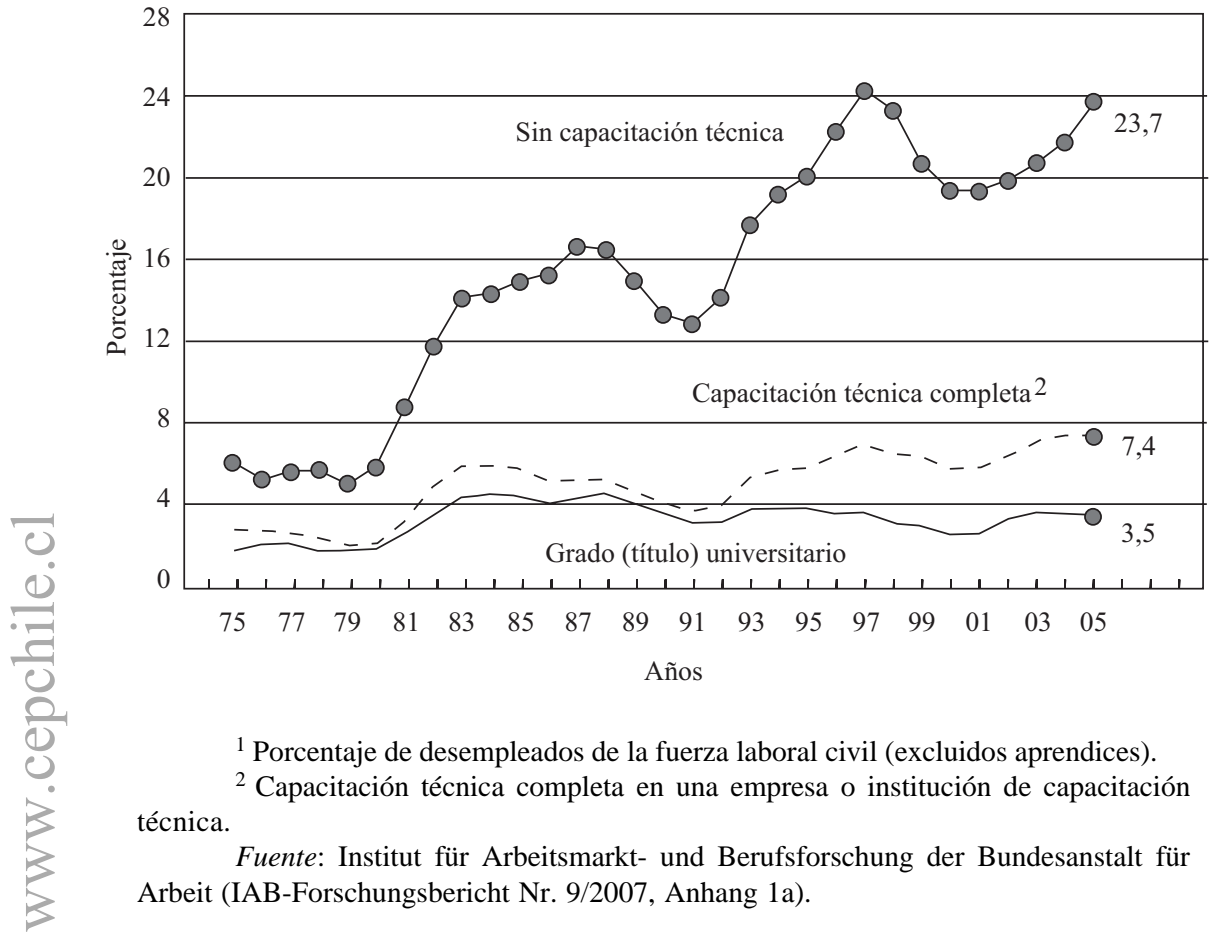


GRÁFICO No 4: TASAS DE DESEMPLEO SEGÚN NIVEL EDUCACIONAL: COMPARACIÓN INTERNACIONAL

(Personas de 25 a 64 años de edad, 2004)

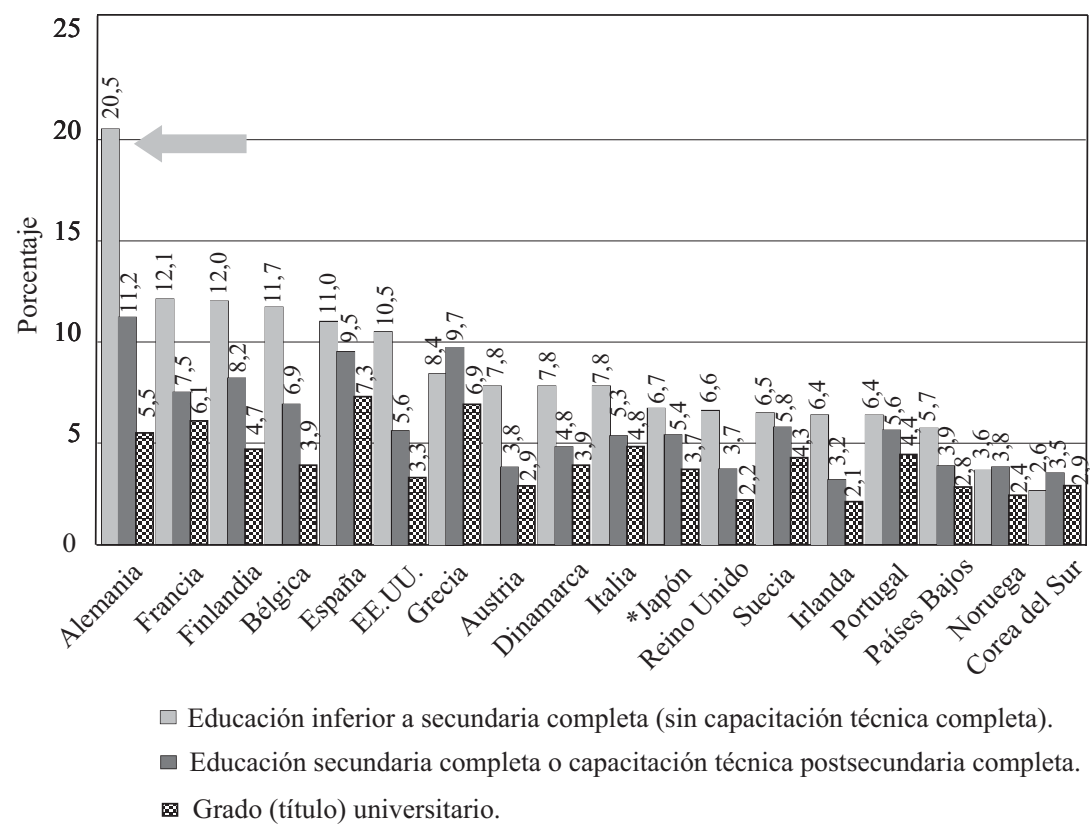

* Japón: 2003.

Fuente: OECD: Education at a Glance, 2006, p. 118 f, Tabla A8.4a.

cundaria completa. Hoy en día Alemania posee el récord de los países de la OCDE en este indicador ${ }^{3}$.

El país de la OCDE que sigue es Francia, cuyo caso es bastante desalentador: enormes tasas de desempleo juvenil, lo cual explica los disturbios que hemos observado en la televisión. Como muchos jóvenes franceses no tienen empleo ni estudian, llegan al extremo de incendiar los buses.

Esa violencia no está ocurriendo en Alemania porque todos los jóvenes están insertos en el sistema escolar, o en programas de capacitación técnica. El problema alemán está en el sector de la mano de obra no calificada no juvenil, es decir mayores de 18 años, entre quienes se observa un alto nivel de cesantía, que se explica por la generosidad del subsidio de desempleo. A mi juicio, esa generosidad también explica en parte la inmigración masiva, sobre todo de ciudadanos turcos, pues al encontrar empleo despla-

\footnotetext{
${ }^{3}$ OCDE es la Organización para la Cooperación y el Desarrollo Económico.
} 
zan a trabajadores alemanes comparables, que cuentan con la ventaja de poder trasladarse al subsidio de desempleo ${ }^{4}$.

Si analizamos la categoría de personas que han completado la educación secundaria, la cifra alemana de desempleo también es más alta que en la mayoría de los demás países, pero la distancia no es tan grande. Y en lo que respecta a las personas con título universitario, en algunos países se registran cifras de desempleo superiores a las de Alemania. ¿A qué se debe esta progresión? En mi opinión se trata de un efecto que denomino "efecto de acordeón”, y que se origina en el Estado benefactor. Supongamos que la distribución salarial es una suerte de acordeón que cuelga de mi mano izquierda, y sus pliegues son los niveles salariales para distintas categorías según grado de calificación. Ahora, ¿cuál es el efecto de un Estado benefactor que ofrece asistencia social y subsidios de desempleo? El hecho de que el Estado de bienestar ofrezca un ingreso mínimo independiente de la calificación implica que el salario más bajo es el más afectado por el monto que el Estado paga por no trabajar.

El segundo salario más bajo, en la siguiente categoría de calificación, también aumenta, debido a procesos de sustitución tanto en la producción (en la demanda de trabajo por parte de los empleadores) como en los hogares (en la oferta de trabajo que hacen los hogares). Tiene que haber cierta distancia entre las categorías de escolaridad, pues la capacitación es productiva. Lo mismo se repite en el tercer salario más bajo, en la categoría subsiguiente. La distribución de salarios de mercado se comprime desde abajo. Este efecto es muy marcado en el extremo inferior de la distribución del ingreso, y pierde fuerza a medida que nos acercamos al extremo superior.

De esta manera, el salario de un ingeniero no se ve afectado por el Estado benefactor. Sin embargo, el salario del trabajador calificado común, que cuenta con algún grado de capacitación, ya es más alto que lo que sería en otras circunstancias, porque aquí el Estado benefactor entra a ofrecer salarios competitivos en el mercado laboral. Y en el nivel inferior tenemos a los trabajadores no calificados, donde se genera un desempleo masivo.

Otra consecuencia de esto es que el salario promedio aumenta, aunque sólo entre los ocupados. Y además los impuestos necesarios para financiar los subsidios a los desempleados reducen el salario neto de impuestos.

\footnotetext{
${ }^{4}$ Ver este argumento en detalle en Sinn, Hans-Werner: "Migration and Social Replacement Incomes: How to Protect Low-Income Workers in the Industrialized Countries Against the Forces of Globalization and Market Integration”, 2005, en International Tax and Public Finance, 12, pp. 275-393.
} 
Algunos autores como Prescott estiman que el problema del desempleo en Europa se origina en los altos impuestos. Pensamos que esa estimación es errónea. Si el desempleo europeo fuera el resultado de altos impuestos personales, entonces el efecto sería el opuesto al observado, ya que mientras más subamos según categorías de calificación y escolaridad, más altas serán las tasas de impuesto marginal sobre el ingreso personal. Es así como deberíamos observar las tasas más altas de desempleo en los segmentos superiores, y tasas inferiores entre los trabajadores que pagan tasas marginales menores, como los menos calificados. Ello no ocurre.

Desde luego, hay otro impuesto marginal que se aplica al trabajo remunerado en empresas, pero éste es implícito. Consiste en la reducción de los subsidios, que se aplica a quienes empiezan a abandonar el desempleo. Esta tasa implícita de impuesto es extremadamente alta en Europa. Pero los impuestos abiertos o explícitos, a los que se suele señalar como la causa del desempleo en Europa, no inciden en esta situación. Y digo Europa, porque observamos efectos similares en la mayoría de los países europeos. En la mayor parte de ellos existe este tipo de ingreso mínimo garantizado, pero en Alemania se aprecia en forma más pronunciada.

El problema también se manifiesta en el grado de desigualdad del ingreso laboral. El Gráfico $\mathrm{N}^{\circ} 5$ presenta el indicador 9/1 de desigualdad del ingreso laboral en varios países. Este indicador es el cociente entre el ingreso medio del decil noveno (donde se encuentran las personas cuyo ingreso está entre los percentiles 81 y 90) y el ingreso medio del primer decil o más pobre, donde están las personas de menor ingreso. Este cociente fue cercano a 3,2 veces en Alemania y Francia en 2005, y sólo levemente más alto en Gran Bretaña. Sabemos que Estados Unidos es un país capitalista donde existe un alto grado de desigualdad, y efectivamente ello se refleja en este indicador, que es cercano a 4,9*. También conocemos el lado negativo de la desigualdad en Estados Unidos. No desearía ir a ciertos barrios de Chicago sin automóvil. En esos barrios las puertas están cerradas debido a la inseguridad.

Pero debemos admitir que los estadounidenses no tienen un problema de desempleo entre los trabajadores no calificados; Alemania y Francia sí lo tienen. Así, una de las repercusiones de la compresión artificial de la distribución del ingreso a través del salario mínimo, o del Estado benefactor que compite ofreciendo un salario de reemplazo alto, es una alta tasa de desempleo entre los trabajadores no calificados.

* Nota del editor: La cifra comparable para Chile es 4,84 (Casen 2006), que se obtiene dividiendo el salario promedio de las personas en el noveno decil del ingreso autónomo del hogar, que fue \$ 442.773 al mes, por el salario promedio de aquellos del primer decil, que fue \$91.553 al mes (ver Mideplán, Trabajo e Ingresos, 2006). 
$\begin{array}{ll}\text { GRÁFICO N }^{\circ} 5: & \text { RAZÓN DE DESIGUALDAD DE SALARIOS }{ }^{1} \text { EN CUATRO PAÍSES } \\ & \text { DESARROLLADOS (1980-2005) }\end{array}$

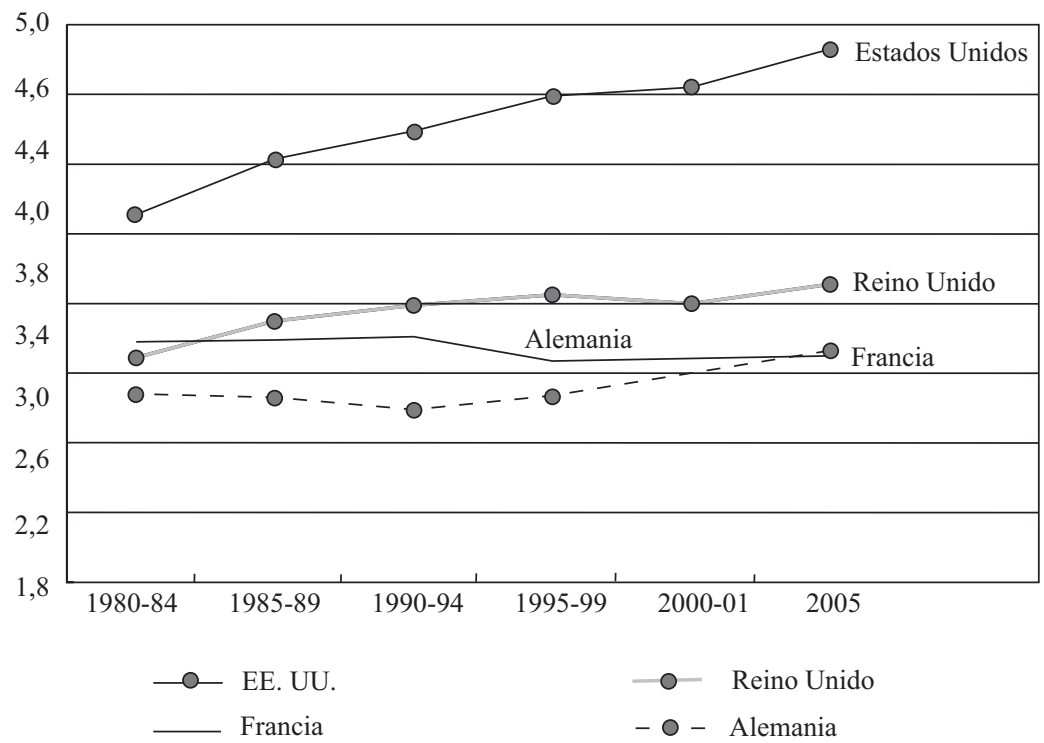

${ }^{1}$ Es la razón entre el salario bruto medio de los deciles noveno y primero, para empleados en jornada completa.

Fuentes: OECD: Employment Outlook, 2004, tabla 3.2, p. 141, y Employment Outlook, 2007, p. 268.

\section{Lecciones de la unificación alemana}

La unificación alemana es un ejemplo drástico de las repercusiones negativas que un Estado benefactor puede tener sobre el empleo y la marcha de la economía. Como todos sabemos, en 1989 cayó el Muro de Berlín y en 1990 se unificaron las dos Alemanias: el sector occidental albergaba al $80 \%$ de la población, y el sector oriental, afortunadamente, sólo al 20\%. Y digo afortunadamente porque la zona este se volvió muy cara. Es como si cada familia occidental tuviera a un hermano del este a quien alimentar, el cual golpea a la puerta y dice: "Aquí estoy, tienen que ayudarme”.

Se esperaba que la unificación alemana traería aparejado un rápido proceso de convergencia económica en Alemania oriental, pues las reglas del juego se basarían ahora en el sistema capitalista propio de Occidente, que es superior. Así pues, se esperaba que Alemania del Este alcanzara 
dentro de un breve período la productividad de Alemania Occidental. El entonces Canciller Kohl anunció que presenciaríamos un panorama floreciente dentro de tres, cuatro o cinco años, lo cual le causaba un enorme entusiasmo. Y daba la impresión de que este proceso de adaptación hacia la plena igualdad entre el Este y el Oeste concluiría al cabo de una década.

¡Qué afirmación tan errónea! Como pueden apreciar en el Gráfico $\mathrm{N}^{\circ} 6$, aquí no hay ninguna convergencia. La productividad de Alemania occidental se indica con el nivel 100 en este gráfico, y se mide como el PIB por persona en edad laboral, lo cual limpia las diferencias demográficas.

A decir verdad hubo una convergencia inicial — contamos con datos a partir de 1991; para el período anterior la información es escasa—, pero se detuvo en el $60 \%$ del nivel occidental. Por supuesto que el desempleo es un factor que incide negativamente en esta medición de productividad. No ha habido convergencia desde mediados de la década de 1990 hasta ahora.

GRÁFICO No ${ }^{\circ}$ P: PRODUCTIVIDAD E INGRESO EN ALEMANIA ORIENTAL ${ }^{1}$ (1989-2005) (Base: Alemania occidental $=100$ )

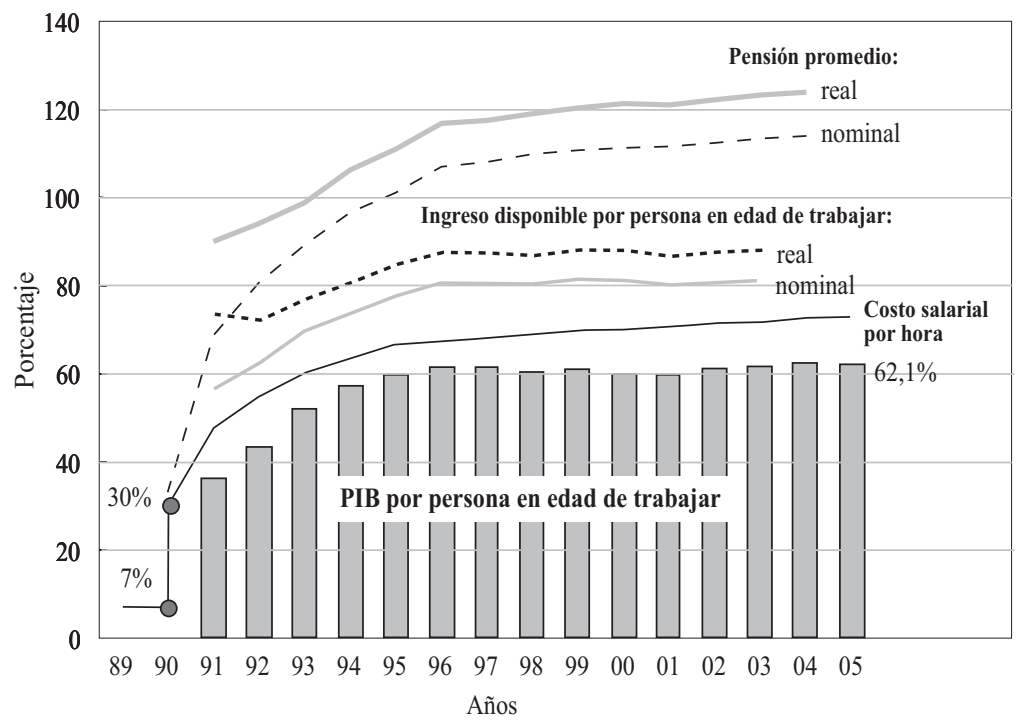

${ }^{1}$ Alemania occidental incluye Berlín occidental; Alemania oriental incluye Berlín oriental. La división de Berlín sigue estimaciones del Instituto Ifo.

Fuente: Estadísticas Bundesamt; Arbeitskreis Volkwirtschaftliche Gesamtrechnungen der Länder, Länderergebnisse, Reihe 1, tabla 1.1 y tabla 13 (marzo 2006), Reihe 1, Band 5, tabla 5.2 y tabla 5.2 (2) (mayo 2006). Poder adquisitivo: cálculos del Instituto Ifo. 
El costo salarial por hora para trabajadores industriales - disponemos de datos confiables en esta área- solía ser el 7\% del salario alemán occidental antes de la unificación. Esta cifra tan baja se origina en que también reflejaba la paridad cambiaria, que era de 4,3 a 1 entre los marcos del Este y el Oeste. Cuando se decretó la convergencia cambiaria 1 a 1 , un marco oriental se transformó numéricamente en un marco occidental, por lo que todos los contratos salariales fueron reconvertidos automáticamente a marcos occidentales. Con esto el costo salarial por hora de Alemania oriental se cuadruplicó el día 1 de julio de 1990, pasando de 7\% a 30\% del costo laboral alemán occidental de la noche a la mañana. Posteriormente aumentaron los salarios negociados por los sindicatos, y el Gráfico N ${ }^{\circ} 6$ muestra cómo estas alzas derivaron en un costo salarial que bordea el $76 \%$ del costo salarial de Alemania occidental en 2005. No hay convergencia desde 1996.

Por cierto que si abrimos las compuertas los niveles de agua se igualarán y con el tiempo probablemente no se observará ninguna diferencia. Pero, en una primera etapa, las fuerzas del mercado tendrían que haber hecho converger las cifras de productividad, dejando para una segunda etapa la convergencia de los salarios. Este orden temporal era necesario debido al déficit inicial de Alemania oriental en maquinaria e infraestructura moderna, y cubrir ese déficit tiene costos de transición que tendrían que ser financiados mediante un excedente de la productividad por sobre los salarios.

Sin embargo, sucedió todo lo contrario: los políticos decidieron aumentar primero los salarios y luego la productividad. La convergencia no ocurrió, porque los empresarios, que debían pagar los salarios altos, dijeron: “¡Un momento! ¿Realmente me conviene incorporarme a ese sistema si no obtengo utilidades?”

El ingreso disponible por persona, que incluye salarios después de impuestos y subsidios, incluidas las pensiones y todo tipo de transferencias provenientes del Estado, convergió más rápido que el ajuste de la productividad, como muestra el Gráfico $\mathrm{N}^{\circ} 6$. En términos nominales, el ingreso disponible por persona equivale al 80\% del de Alemania occidental. En términos reales corresponde al 90\%, porque los precios de algunos bienes y servicios son inferiores a los occidentales. Las pensiones promedio llegan incluso al 100\% en términos nominales, y al 120\% en términos reales, comparadas con el nivel occidental. Se demostró una gran generosidad al transformar las fórmulas de pensión de Alemania Oriental en equivalentes a las de Alemania Occidental. Fue una decisión política que resultó más generosa que lo necesario, pues no tomó en cuenta las diferencias de precios, y supuso un enorme costo financiero. 
También resulta interesante comparar los salarios por hora en Alemania oriental con los de otros competidores. Una vez más, el Gráfico $\mathrm{N}^{0} 7$ usa el nivel de Alemania occidental como 100. El más bajo es el salario por hora portugués, que actualmente equivale a aproximadamente un cuarto del nivel de Alemania occidental. A continuación viene el salario por hora en Italia. El salario por hora estadounidense es $25 \%$ inferior al costo laboral por hora en Alemania.

La curva para Alemania oriental es la que ya conocemos del Gráfico $\mathrm{N}^{\circ}$ 6. Como podemos apreciar, ya a fines de 1992, dos años después de la unificación, el salario por hora de Alemania oriental superó el salario por hora irlandés. Y luego, transcurridos otros dos años más, alcanzó el nivel del salario por hora estadounidense e italiano. Desde entonces se ha mantenido más o menos invariable en relación con Alemania occidental: en el Gráfico $\mathrm{N}^{\mathrm{o}} 7$ aparece como un $75 \%$ del salario de Alemania occidental. Ya no converge.
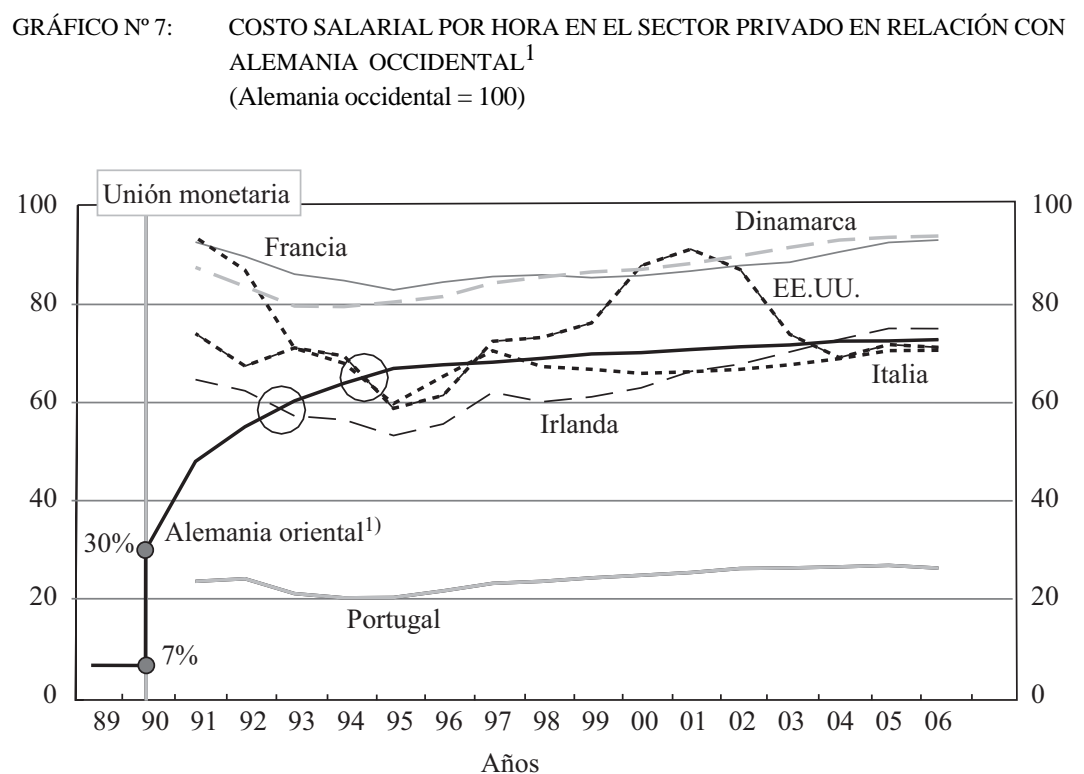

${ }^{1}$ Alemania occidental incluye Berlín occidental; Alemania oriental incluye Berlín oriental. La división de Berlín sigue estimaciones del Instituto Ifo.

Fuente: Dinamarca, Francia, Irlanda, Italia, Portugal, Estados Unidos y Alemania occidental: Institut der deutschen Wirtschaft Köln. Alemania occidental y Alemania oriental: Arbeitskreis Volkswirtschaftliche Gesamtrechnungen der Länder, agosto 2007. IAB. Cálculos del Instituto Ifo. 
Esta evolución no fue una consecuencia de las fuerzas del mercado. Ellas nunca habrían podido ocasionar un fenómeno semejante. Todo fue producto de decisiones políticas. En primer lugar, tenemos al Estado benefactor. Su diseño original, previo a la caída del muro, era similar al occidental. De la noche a la mañana, los habitantes de este país ex comunista comenzaron a recibir el ingreso de reemplazo de Alemania occidental, generando el salario mínimo implícito que ya explicamos en las secciones iniciales.

El nivel de dicho salario mínimo implícito depende de la composición de la familia, como indica el Gráfico $\mathrm{N}^{\circ}$ 8. También depende de la remuneración adicional mínima que una persona necesitaría para estar dispuesta a dejar de percibir lo que de otro modo habría ganado trabajando en el mercado negro o en el hogar. Digamos que esta remuneración adicional mínima son 5 euros por hora, cifra que en Alemania es modesta.

Como vemos, el Estado benefactor comenzó a pagar salarios que fluctuaban entre $60 \%$ y $85 \%$ del nivel aplicado en Alemania occidental. En dichas circunstancias, la opción de pagar salarios bajos sencillamente deja de existir, porque el trabajador siempre puede dirigirse a una oficina del gobierno y decir: "Aquí estoy. Denme el dinero, porque no tengo empleo", en vez de trabajar en el mercado a cambio de un salario bajo.

La unificación también creó una fuente de financiamiento externa para Alemania oriental. Esto generó problemas similares a los que enfrentó

GRÁFICO No ${ }^{\circ}$ : SALARIO MÍNIMO IMPLÍCITO EN ALEMANIA ORIENTAL

(Subsidio de desempleo más 5 euros por hora)

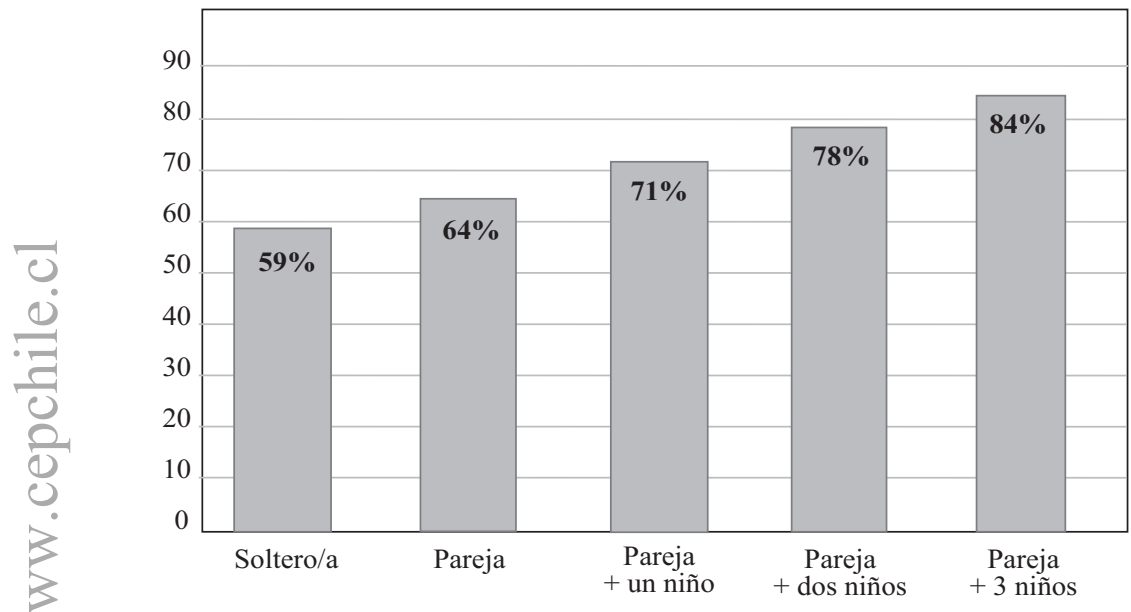

Fuente: Instituto Ifo. 
Holanda luego de encontrar gas natural en su territorio, pues ello trajo consigo un súbito flujo de recursos y dinero. Y así Holanda construyó una nueva industria en torno al gas natural: los trabajadores fueron tentados a abandonar otros sectores de la economía e incorporarse al de la producción de gas natural; los salarios se dispararon y los demás sectores decayeron. En los textos de economía esta decadencia sectorial se conoce como la "enfermedad holandesa", la cual había sido analizada mucho antes de que tuviera lugar la unificación alemana.

Alemania oriental también sufre de la "enfermedad holandesa", pero su origen no fue una nueva industria, sino la llegada del Estado benefactor de Alemania Federal. En Holanda la industria del gas absorbía trabajadores, pagándoles salarios altos; y en Alemania el Estado benefactor absorbe trabajadores, pagándoles salarios altos por no hacer nada.

Ahora bien, ¿cuánto cuesta todo esto? Para dar una idea, el Gráfico № 9 resume la información más actualizada del Instituto Ifo, que dirijo: la demanda agregada o "absorción total” en Alemania oriental alcanzó a 416.000 millones de euros en 2006. La absorción es la demanda total de bienes y servicios, incluyendo el consumo privado, la inversión privada en capital físico y la demanda del Estado. La demanda total de bienes normalmente equivale al PIB, pues lo que producimos es lo que podemos consumir.

Pero si hay otros países que nos ayudan con donaciones, entonces podemos consumir más de lo que producimos. También, si otros países nos prestan o financian inversiones físicas dentro de nuestro territorio, hay más recursos para gastar. En Alemania oriental la producción propia (PIB) alcanza sólo a 287.000 millones de los 416.000 millones de euros. De la diferencia, 98.000 millones de euros corresponden a transferencias fiscales netas desde Alemania occidental a Alemania oriental, por la vía del presupuesto federal. Un ítem es la inversión pública: si se construye una autopista en Alemania oriental, el dinero proviene del Estado, desde Alemania occidental. Otro ítem es el seguro de desempleo (cotizaciones e impuestos de ciudadanos de Alemania occidental que se canalizan hacia los desempleados del Este). Un tercer ítem es el gasto en pensiones (ya me referí a lo generoso que es el sistema de pensiones en Alemania oriental); y así sucesivamente. Incluso en el sistema de salud se produce una redistribución implícita desde el Oeste hacia el Este. A esto se agrega el flujo de capital desde el Oeste, que alcanzó en 2006 a 31.000 millones de euros (normalmente desde Alemania occidental, pero también desde otros países occidentales). La suma de todo esto explica por qué sus habitantes pueden consumir muchísimo más que lo que producen.

A decir verdad, de cada euro que Alemania oriental utiliza para comprar, 31 centavos son donaciones del Oeste y sólo 60 centavos se ganan o 

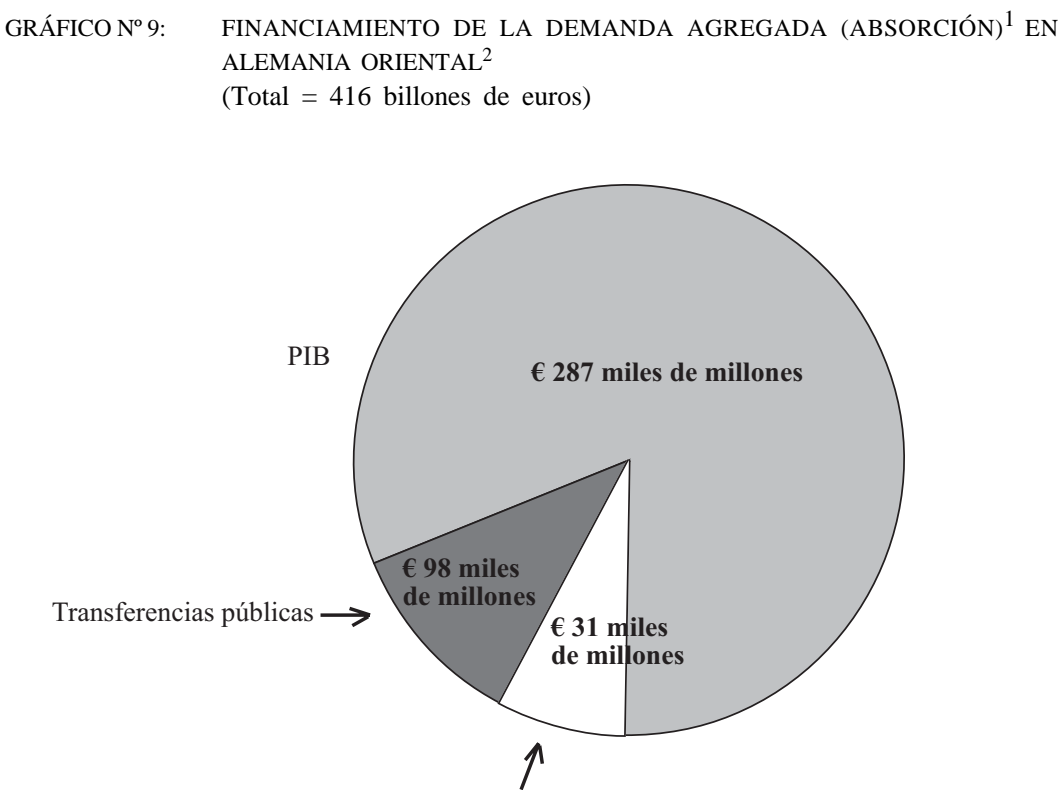

Ingreso neto de capitales

1 Absorción es la suma de inversión privada, consumo privado y gasto del sector público en bienes y servicios.

${ }^{2}$ Alemania oriental incluye Berlín oriental. La división de Berlín sigue estimaciones del Instituto Ifo.

Fuente: Arbeitskreis Volkswirtschaftliche Gesamtrechnungen der Länder; cálculos del Instituto Ifo.

producen en el Este. ¿Es mucho? ¿Es poco? Bueno, a este flujo de recursos los economistas lo denominan déficit de la balanza comercial. Por lo general hablamos de la balanza comercial de los países, pero en este caso hablamos de la balanza comercial de una región, Alemania oriental.

¿Cuán amplio es el déficit comercial de Alemania oriental en relación con su PIB? El Gráfico N 10 ofrece una comparación con otros países. Alemania como un todo tiene un superávit con respecto al resto del mundo. Irlanda tiene un gran superávit. Pero hay países que tienen déficit. Como todos saben, Estados Unidos tiene un déficit gigantesco, pero con relación al PIB hay otros países cuyo déficit es aun mayor: Grecia, Portugal e Israel. O consideremos el caso de la zona del Mezzogiorno italiano, en el sur de Italia, que padece un déficit comercial crónico y recibe recursos del norte de Italia equivalentes al 13\% del PIB regional en el sur del país. De modo que 
GRÁFICO N 10: DÉFICIT DE LA BALANZA COMERCIAL: COMPARACIÓN INTERNACIONAL (\% del PIB 2004)

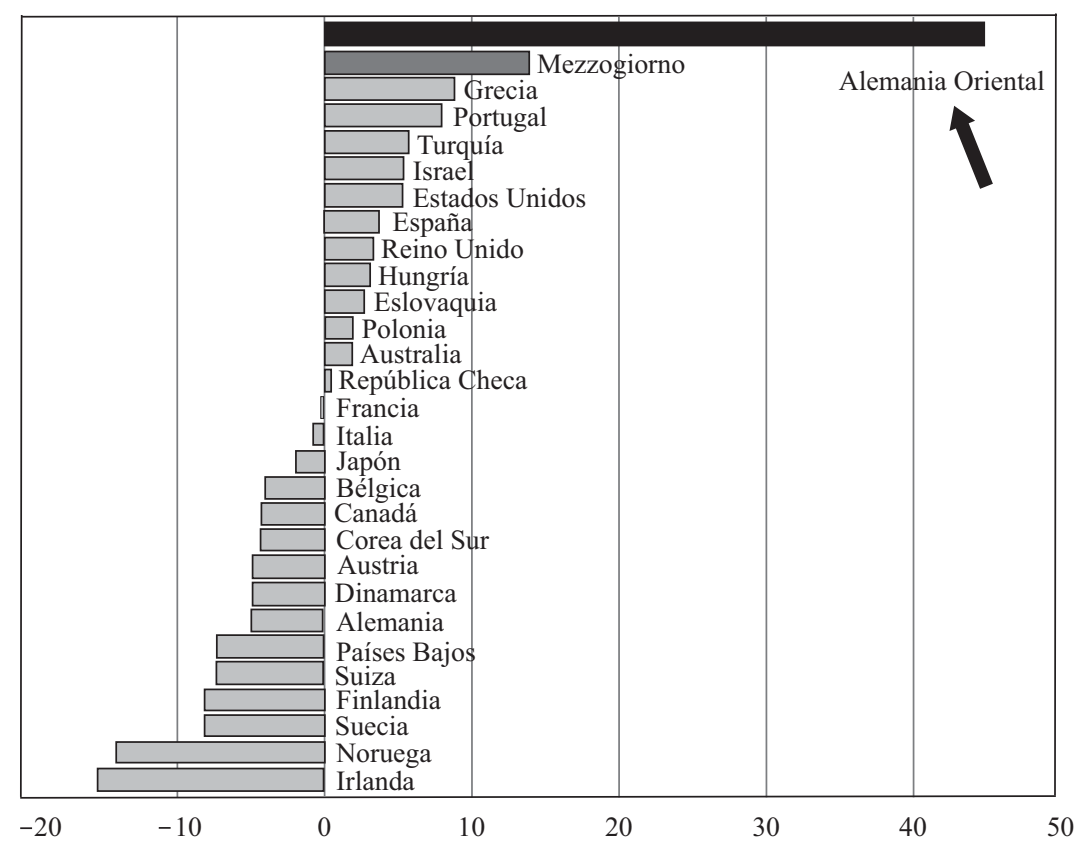

Fuentes: Países europeos: Eurostat. Israel y Corea del Sur: Banco Mundial, World Development Indicators. Mezzogiorno: SVIMEZ, Rapporto 2005, Sull'Economia del Mezzogiorno, tabla 1. Alemania oriental (incl. Berlín oriental): Arbeitskreis Volkswirtschaftliche Gesamtrechnungen der Länder. Estadísticas de Bundesamt. Cálculos del Instituto Ifo.

sus habitantes pueden consumir más de lo que producen porque obtienen los recursos.

¿Y qué tan alta es la cifra de Alemania oriental en este contexto? Es enorme; es mayor que la de cualquier otro país del mundo. Jamás en la historia ha existido una región en el mundo de extensión tan considerable que reciba semejante transferencia relativa de fondos en forma regular y permanente. Afortunadamente Alemania occidental es un país rico: la donación equivale al 4,5\% de su PIB, de modo que puede financiarla sin sufrir demasiado.

Sin embargo, lo anterior tuvo algunas repercusiones en materia de crecimiento. El Gráfico No 11 muestra que los avances económicos de Alemania occidental desde mediados de la década de 1990 no son muy alentadores. Comparemos el crecimiento alemán durante este período de 12 años 
GRÁFICO N ${ }^{\circ}$ 11: PIB REAL EN ALGUNOS PAÍSES DE LA UNIÓN EUROPEA

(Crecimiento acumulado 1995-2007 en precios 1995; 1995 = 100)

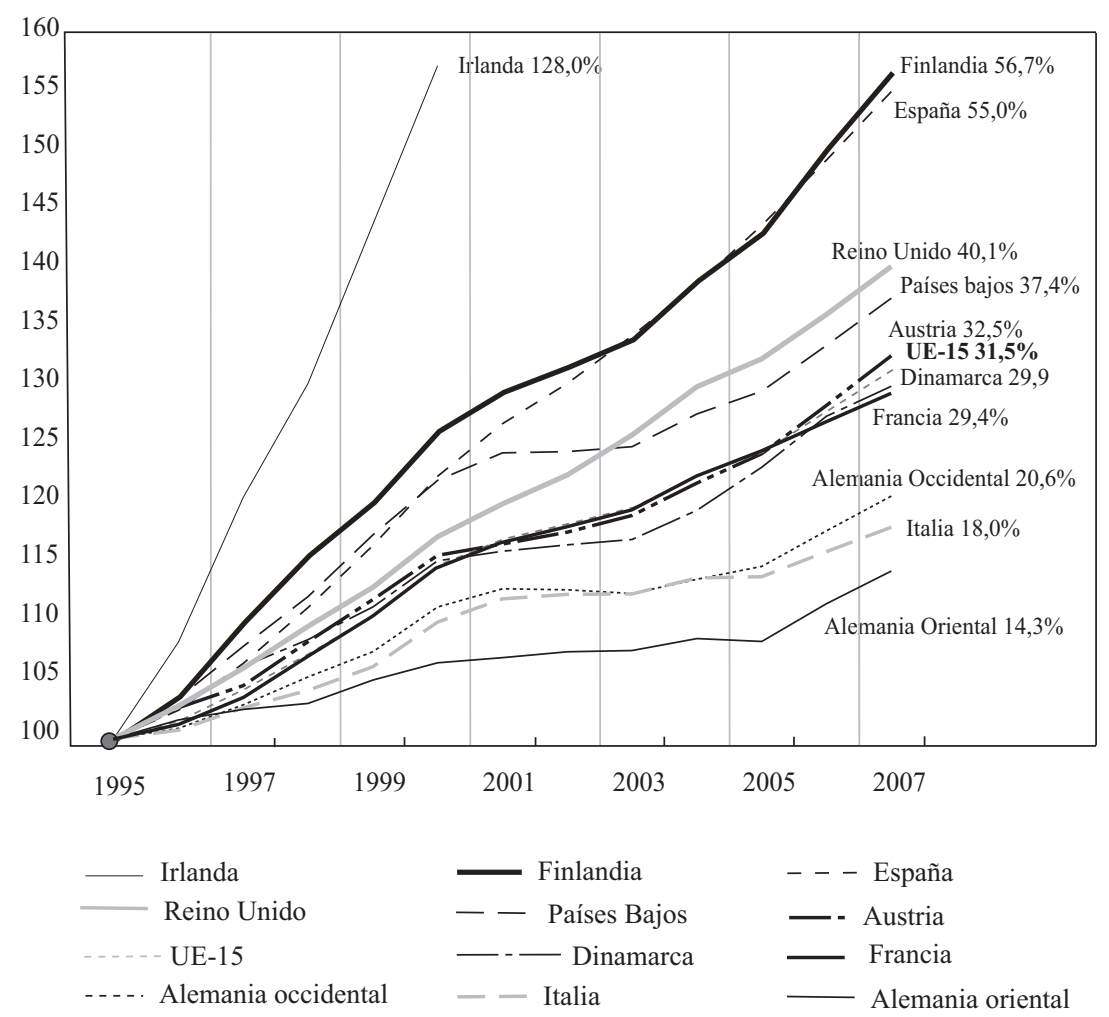

Fuentes: Países europeos: Eurostat; Oficina de Estadísticas de Alemania; cálculos y pronósticos del Instituto Ifo (diciembre 2007).

(1995-2007) con el de otros países. Se observa en este gráfico que el promedio de la Unión Europea (los antiguos miembros, UE-15) creció 31,5\% en términos reales durante un período de 12 años. Irlanda es el campeón, pues creció $128 \%$ en 12 años, más del doble. Se trata de un milagro económico similar al experimentado por Alemania Occidental en la década de 1950. Finlandia sufrió una crisis de transición, porque habían exportado a Rusia por años y esa demanda colapsó en 1990. Los finlandeses sufrieron una gran recesión, comparable con la depresión mundial: la tasa de desempleo llegó a 30\% en 1991, pero luego se recuperaron y lograron crecer gracias a Nokia y otras empresas (Nokia representa el $45 \%$ de las exportaciones finlandesas). 
Luego vienen España y Gran Bretaña. Si bien Margaret Thatcher ya no estaba en el poder en el período cubierto por el Gráfico $\mathrm{N}^{\circ} 11$, a mi juicio esta cifra es fundamentalmente resultado de su gestión. Gran Bretaña se encontraba en muy mal pie en los años setenta. A mediados de esa década su ingreso per cápita era 50\% del de Alemania. Los británicos habían ganado la guerra, pero habían perdido la paz. Alemania estaba en auge, mientras Gran Bretaña se había rezagado. Luego fue elegida Margaret Thatcher, y en la actualidad los británicos han alcanzado a Alemania en cuanto a ingreso per cápita, y siguen teniendo una alta tasa de crecimiento. Los resultados de Holanda no son los más altos, pero superan con creces al promedio de la Unión Europea.

Llegamos a los más rezagados: Italia, con sólo $18 \%$ de crecimiento durante ese período. Alemania occidental obtuvo un resultado ligeramente superior, con un crecimiento de 20,6\% durante ese mismo lapso. En el último tiempo parece que estamos en pie de igualdad con Italia en cuanto a exhibir la tasa de crecimiento más baja de toda Europa. Podríamos incorporar a todos los demás países europeos -incluso a los de Europa del Este, hasta Rusia- al Gráfico № 11, y así y todo la tasa de crecimiento italiana seguiría siendo la más baja. No existe ningún otro país con resultados tan deficientes. Afortunadamente, la tasa de crecimiento de Alemania aumentó ligeramente. Como podemos observar, Alemania oriental no creció al mismo ritmo que Alemania occidental (la unificación fue en 1991), pese a que esta última exhibió una de las tasas de crecimiento más bajas de toda Europa. Los resultados de Alemania oriental fueron aun peores. El mal desempeño de las dos Alemanias obedece probablemente a la influencia del mercado laboral: si no damos empleo a los trabajadores, ¿cómo puede haber crecimiento?

\section{Lecciones de las reformas de Schröder (Agenda 2010)}

En su segundo período de gobierno, el Canciller Schröder demostró arrojo. Como no tenía nada que perder, dijo: "Apliquemos una política audaz”. ¿Qué hizo? Modificar el Estado benefactor con su "Agenda para el 2010”. Para reducir el monto del subsidio de cesantía para beneficiarios de mayor edad, eliminó la proporcionalidad al salario del subsidio de cesantía de segundo nivel. Además reformó el sistema de asistencia social propiamente tal. El efecto fue otorgar más dinero a quien trabaja y menos a quien permanece inactivo: los desempleados recibieron menos fondos. Pero al mismo tiempo la reforma permitió que aquellos que trabajaran pudiesen se-

guir percibiendo una parte del dinero que el Estado ofrecía como ingreso de 
reemplazo. De esta forma se agregó un nuevo elemento, mediante el cual se redujo el salario mínimo implícito en el sistema de seguridad social alemán.

Este conjunto de reformas dio resultado: en los dos años posteriores a la fecha de máximo desempleo, Alemania ha recibido el aporte laboral de 400.000 trabajadores adicionales, del que antes carecíamos. Son 400.000 nuevos empleos de baja remuneración, pero sin bajos salarios ellos no habrían sido creados. Por añadidura, el número de empleos creció durante el año 2006, en promedio, en 1,6\% — debido probablemente al ciclo económico-, pero para las personas mayores de 50 años el incremento en el número de empleos fue de 4,9\%. Esto puede ser atribuido a que se acortó el período durante el cual las personas mayores podían recibir subsidios de cesantía. Esto se explica porque dichas personas tuvieron que mov ilizarse y buscar algún puesto y aceptar empleos de baja remuneración que estaban disponibles.

Tal vez el Gráfico $N^{\circ} 12$ es el que mejor demuestra el éxito de esta política. Una de las curvas entrega el número de desempleados en Alemania occidental desde 1970. En esta etapa estuvo en el poder el primer gobierno

GRÁFICO No 12: $\quad$ DESEMPLEO ${ }^{1)}:$ 1970-2008

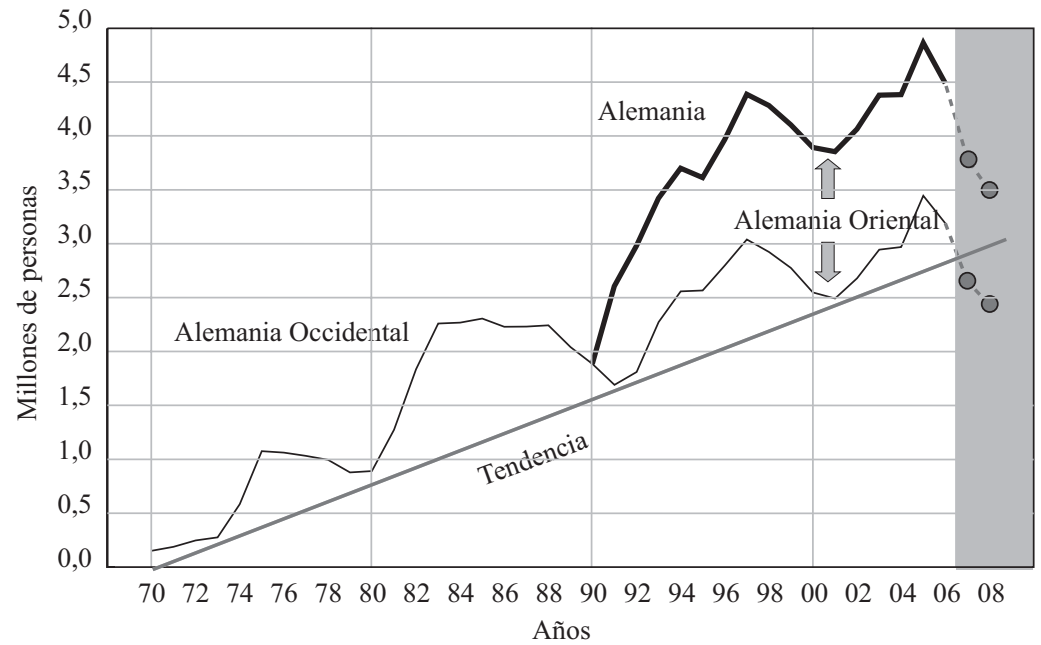

1) Alemania occidental incluye Berlín occidental; Alemania oriental incluye Berlín oriental. Distribución regional de Berlín, según estimaciones del año 2001 del Instituto Ifo.

Fuentes: Bundesagentur für Arbeit; 2007 y 2008: pronósticos del Instituto Ifo (diciembre 2007). 
socialdemócrata de la posguerra, que introdujo el Estado benefactor expandido que tenemos hoy en día. Como podemos apreciar en el Gráfico № 12 , el resultado fue un enorme aumento del desempleo, de acuerdo con una tendencia lineal. Si bien los ciclos económicos decenales influyen, se observa una tendencia ascendente. Luego se produce la unificación alemana, que trajo consigo un número adicional de desempleados.

En 2005 aparece un nuevo elemento, que a mi juicio es lo que introducen las reformas de Schröder. Para los años 2007 y 2008 —pronósticos que son bastante válidos a mi juicio- observamos una marcada disminución en los niveles de desempleo. Ya en 2007 Alemania se sitúa, por primera vez en 37 años, bajo de la línea de tendencia de aumento del desempleo. Se trata de un acontecimiento muy significativo. Aun cuando el mundo se encuentra en un período de auge, el aumento del empleo en 2007 es un fenómeno que no podría explicarse meramente por la bonanza económica que vivió el mundo ese año. Cuando en los años ochenta Holanda reformó su mercado laboral en forma similar, aumentó su empleo, y ahora Alemania replicó ese resultado.

Las reformas tuvieron un segundo efecto: dos millones de personas —un millón en el Este y un millón en el Oeste-comenzaron a recibir menos dinero del Estado que antes. Esto ha provocado reacciones políticas que en este momento (fines de 2007) estamos afrontando: ha crecido un nuevo partido de izquierda, que se ofrece como alternativa para esos ciudadanos desilusionados. La reacción defensiva de la Social Democracia ha sido moverse a la izquierda, lo que le costó el cargo a Schröder.

Alemania se encuentra hoy, a fines de 2007, en medio de un debate sobre cuáles deben ser los pasos futuros. Muchas personas, a decir verdad la mayoría, desean torcer el curso de la historia y volver al pasado. Existe una mayoría que se opone a las reformas de Schröder. Y los partidos de izquierda se encuentran organizando la contraofensiva, que probablemente veremos desplegarse durante los próximos dos años en Alemania. Y otros dicen: "No, las reformas de Schröder han sido acertadas, avanzaron en la dirección correcta y deseamos que se siga aplicando ese enfoque".

Pueden distinguirse dos bandos. Por una parte, aquellos que pretenden revertir las reformas de Schröder, e incluso desean crear un salario mínimo legal, que hasta ahora no ha existido en Alemania, para así contrarrestar la depreciación de los salarios causada por las medidas de Schröder. Y por otra parte, aquellos que dicen: "No. Ampliemos la distribución de los salarios. Permitamos que el acordeón vuelva a expandirse, porque ello trae consigo nuevos empleos que necesitamos con urgencia; podemos ayudar a las personas afectadas de otra manera, entregándoles 
subsidios estatales adicionales mientras trabajan". "No les paguen por estar inactivos; denles más dinero a condición de que efectivamente trabajen”5. Esta última es la estrategia del ingreso mínimo condicional a trabajar.

Me parece que Alemania se encuentra en una encrucijada. Y muchos países europeos - e incluso Chile - deben considerar las opciones disponibles. Existen cuatro alternativas con respecto a cómo mantener los objetivos sociales en una época de globalización. La globalización supone una competencia de parte de los ex países comunistas que ofrecen mano de obra barata. El 28\% de la humanidad, desde Polonia hasta China, y si le agregamos India estamos hablando del 45\% de la población mundial, está ofreciéndose en el mercado laboral mundial. Lo anterior produce una disminución de muchos salarios en los países occidentales. Ahora bien, ¿cómo se puede contrarrestar esta caída?

La primera opción es educar mejor a nuestra fuerza de trabajo. Esta opción tiene muchas ventajas, así que hay que aplicarla. Pero requiere toda una generación para que funcione; es eficaz, pero toma mucho tiempo.

La segunda opción es insistir en el salario mínimo implícito creado por el Estado benefactor, e incluso fortalecerlo con un salario mínimo legal, con lo cual el sistema actual parecería quedar blindado. Sin embargo, esta política preservaría los salarios altos a costa de un aumento del desempleo entre los trabajadores menos calificados — dada la presión de las fuerzas de la globalización-, y además representaría un costo fiscal mucho mayor.

El Gráfico $\mathrm{N}^{\circ} 13$ presenta cálculos sobre las repercusiones de esta estrategia. Muchas personas trabajan por menos de 7,50 euros por hora en Alemania occidental, pues para ellos el salario mínimo implícito es menor. Ellos son el $11 \%$ de la fuerza de trabajo. La medida propugnada por la izquierda sería crear un salario mínimo legal de 7,50 euros por hora para todos los trabajadores. Luego, el empleo del $11 \%$ del total de la fuerza de trabajo se vería amenazado, pues el empleador se vería forzado a elegir entre subir el salario por hora a 7,50 euros, o cerrar esa vacante. Una parte de estas personas, no todas por cierto, se quedaría sin empleo. Si suponemos que la elasticidad al salario de la demanda por trabajo de parte de los empleadores es 0,75 , entonces otras 800.000 personas $-3,1 \%$ de la fuerza laboral- pasarían a engrosar el grupo de los desempleados.

Y si realizamos el cálculo análogo para Alemania oriental, donde la distribución salarial se inclina aun más hacia la izquierda, de forma que el $25 \%$ de los trabajadores recibe actualmente salarios inferiores a 7,50 euros,

${ }^{5}$ Éste es también el concepto que guía el impuesto a la renta en el modelo de Winsconsin, el estado del centro-norte de los Estados Unidos. 
$\begin{array}{ll}\text { GRÁFICO No } 13: & \text { PÉRDIDAS DE EMPLEO EXPLICADAS POR EL SALARIO MÍNIMO } \\ \text { (Supuesto: el salario se fija en 7,50 euros) }\end{array}$

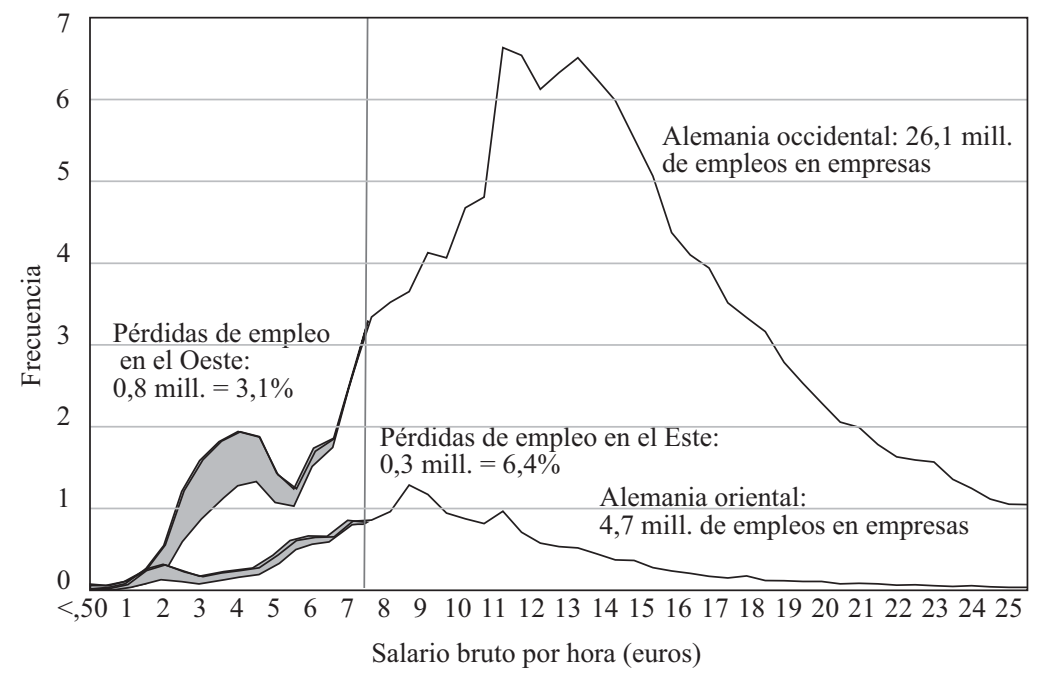

Fuente: Instituto Ifo.

encontramos que el 6\% de ellos —unas 300.000 personas- se quedaría cesante. A mi juicio, una estrategia que envía al desempleo a otro 1,1 millón de personas sería realmente desastrosa para Alemania. No creo que esta estrategia pueda mantenerse en el largo plazo.

La tercera opción es aplicar la receta escandinava. Lo que hacen los escandinavos es expandir el empleo del sector público y trasladar allí a todas las personas que no encuentran empleo en el sector privado. Estoy simplificando un poco la fórmula, pero la aproximación es bastante buena. En Dinamarca y en Suecia el 33\% de la fuerza de trabajo asalariada trabaja en el sector público. La cifra análoga promedio para los países de la Unión Europea de 15 miembros es de 18,5\%, y para Alemania es un 12,5\%. Vemos que esa política también resulta costosa fiscalmente, pero al menos los escandinavos pagan a la gente por hacer algo, lo cual ayuda a justificar el costo fiscal. Otro aspecto es que un 33\% de los trabajadores está bajo las órdenes de las autoridades políticas.

En cuarto lugar está la estrategia de los subsidios al ingreso. Aquí se acepta más desigualdad en la distribución del ingreso, pero ello se atenúa entregando subsidios salariales, de modo que la suma de los salarios bajos y el subsidio individual satisfaga nuestros estándares de ingreso mínimo social. En mi opinión ésta es la única vía por la cual Alemania puede avanzar, amén de que es sustentable en el tiempo. 
Todos los países, incluso Chile, deben escoger una de estas cuatro alternativas. En estos tiempos de globalización y de competencia laboral de parte de los ex países comunistas, los salarios de la mano de obra no calificada son objeto de presiones a la baja. Se trata de un fenómeno muy poderoso, que seguirá siéndolo durante las próximas décadas. Estaremos todos muertos antes de que el mundo llegue a encontrar un nuevo equilibrio económico tras la integración de los ex países comunistas. De modo que debemos considerar seriamente estas cuatro alternativas.

El Instituto Ifo ha propuesto que Alemania sustituya el sistema de asistencia social actual por un modelo que denominamos "asistencia social activadora". Lo que pretendemos es que todos reciban un ingreso básico. Los subsidios no se suspenderían una vez que el beneficiario comience a trabajar. Queremos dar a la gente la posibilidad de trabajar y mantener la asignación básica — hasta 500 euros al mes—. Sólo cuando la persona logre ingresos salariales más significativos comenzaríamos a disminuir gradualmente el subsidio. Como mantener los subsidios sin suspenderlos cuando el beneficiario trabaja le costaría más dinero al fisco que en la actualidad, proponemos compensar al fisco reduciendo levemente el subsidio o asignación base, en un tercio de su nivel actual.

Ambas medidas agilizarían el mercado laboral, porque el Estado entregaría más dinero mientras la gente está trabajando, y menos mientras está inactiva. De modo que el salario mínimo implícito que los trabajadores exigen a los empleadores privados se reduciría, lo mismo que el salario real sin considerar subsidios, y por tanto se crearían más empleos. Pero ello no quiere decir que el ingreso real total vaya a disminuir, pues los subsidios que proponemos mantendrían el ingreso total actual para todos los trabajadores de menor salario (hasta 500 euros al mes).

Nuestra propuesta contiene una tercera medida porque la Constitución alemana indica que el actual nivel de ingreso mínimo no puede descender, y no es nuestra intención infringirla. ¿Qué proponemos hacer respecto de las personas que no encuentren empleo a pesar de nuestra eficaz estructura de incentivos? Ese evento no puede descartarse, así que debemos garantizar el ingreso actual de una manera compatible con los demás incentivos laborales que proponemos. Nuestra tercera medida es que los municipios ofrezcan contratos a plazo fijo a todo el que no encuentre empleos normales, al estilo escandinavo. Si no encontramos empleo en la economía privada, podemos dirigirnos a la comunidad local y decir: "Aquí vengo a ofrecer mis servicios laborales a cambio del ingreso básico”.

¿Y qué debe hacer el gobierno local con estas personas que vienen a ofrecer sus servicios? ¿ Todas ellas van a dedicarse a asear los parques? No 
hay suficientes parques. Más bien proponemos permitir al municipio arrendar los servicios de estas personas al sector privado, a cambio de un honorario o precio libremente negociado entre el municipio y los compradores privados del suministro. Esperamos que el precio de este contrato de suministro de mano de obra sea menor que el ingreso mínimo pagado a los trabajadores por el municipio, por lo que habría un déficit que sería cubierto por el fisco. Igual es fiscalmente conveniente que exista este suministro de mano de obra, porque el precio del suministro sería superior a cero, en el entendido de que a precios bajos siempre habría demanda de parte del sector privado. Éste es un sistema que ha dado resultado en Holanda.

El precio del suministro de mano de obra es independiente del ingreso de estas personas. Ese ingreso es el monto del subsidio que reciben actualmente sin ninguna deducción. La diferencia es que dichas personas tendrán que prestar servicios laborales como condición para obtener subsidios, y esos servicios serán canalizados hacia el sector privado formal.

Una persona podría mantenerse trabajando en el suministro municipal de mano de obra de manera permanente, pero no le resultaría atractivo, porque tendría que trabajar en jornada completa. Dentro del esquema propuesto, al trabajar medio día en el sector privado se obtendría el mismo dinero. De modo que con este sistema de empleo municipal directo siempre resulta más atractivo trabajar directamente en el sector privado. Pero si la persona insistiera o si la demanda privada por trabajo no calificado sufriera una baja imprevista, podrá mantener ese empleo y el ingreso de manera permanente.

Además, esta propuesta destruiría el mercado negro del trabajo. ¿Por qué? Porque quienes solían reclutar trabajadores en el mercado negro ya no encontrarán mano de obra. Sus antiguos trabajadores no tendrán tiempo, pues su jornada laboral en el municipio será de ocho horas. Por lo tanto, los empleadores deberán recurrir al área privada. Si necesitamos fontaneros, ya no los encontraremos en el mercado negro, pues los que hacían esa labor estarán trabajando para un municipio. Entonces habrá que recurrir a un fontanero privado que no trabaja en el mercado negro. Este fontanero privado podrá contratar ayudantes en el municipio (vía contrato de suministro). Se trata de un método mediante el cual la economía subterránea es canalizada hacia la economía legal.

Para ilustrar los verdaderos alcances de nuestra propuesta, comparemos el ingreso bruto mensual y el ingreso neto. El Gráfico $\mathrm{N}^{\circ} 14$ describe el actual sistema tributario alemán, incluyendo todas sus complejidades y considerando las reformas de Schröder, pero sin nuestra propuesta. Presenta el caso de una familia con dos hijos. En el eje vertical están los posibles 
GRÁFICO N 14: LA “CARA NORTE” DEL MONTE EIGER: ALEMANIA EN 2005, CONSIDERANDO LAS REFORMAS DE SCHRÖDER

(Efectos del empleo del subsidio de cesantía en una familia con dos hijos. Considera: ingreso laboral mensual, subsidio de cesantía nivel II, asignación familiar, bono por hijo, impuesto al salario y cotización del trabajador a la seguridad social.)

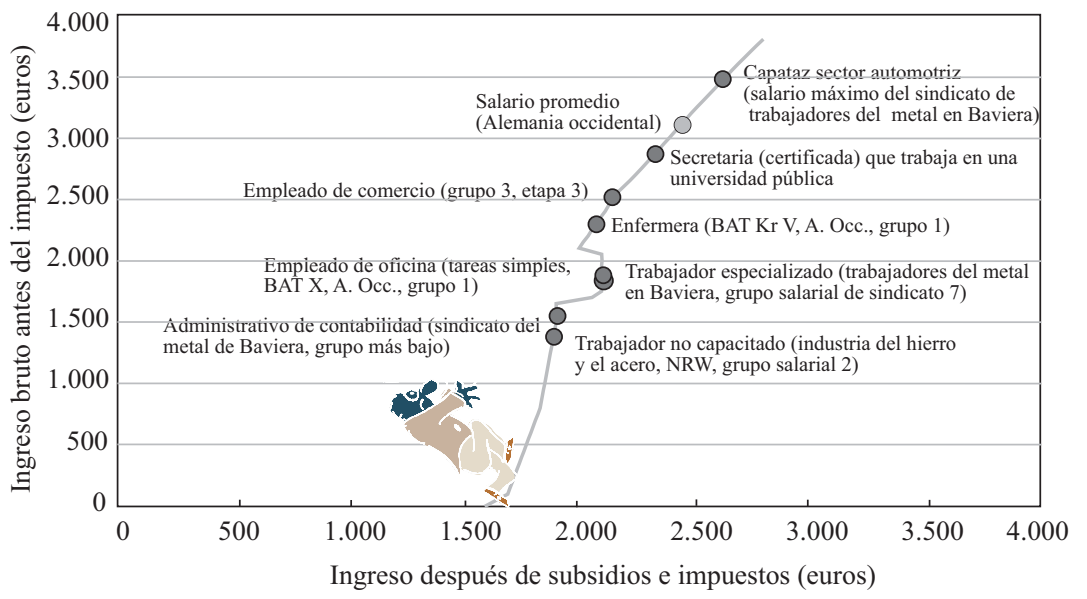

Fuente: Cálculos del Instituto Ifo.

valores para el ingreso familiar, y en el eje horizontal se muestra el ingreso neto resultante, ambos en euros por mes. Si nadie en esta familia trabaja, el ingreso bruto es cero, y el ingreso neto es de 1.600 euros al mes. Si algún miembro trabaja en un empleo de jornada parcial y gana 500 euros al mes, entonces el ingreso neto será un poco más alto, digamos 1.700 euros al mes. $\mathrm{Si}$ alguien gana 1.500 euros al mes trabajando, el ingreso neto sería casi el mismo. Lo notable es cuán poco varía el ingreso neto respecto al caso de quien no trabaja.

De modo que en el mercado laboral alemán hay que trepar una montaña muy escarpada para aumentar el ingreso neto. Yo denomino a la curva que muestra el Gráfico № 14 como la "cara norte" del monte Eiger (que es tan escarpada que fue escalada por primera vez recién en 1938). Y esto es lo que la gente tiene que hacer en Alemania para aumentar su ingreso neto. Se trata de un enorme esfuerzo en términos del ingreso bruto que hay que ganar para salir adelante en términos netos. Es una tarea sumamente difícil.

El Gráfico No 14 también indica dónde se ubican algunos empleados representativos, incluyendo los de ingresos más bajos. Si bien estos individuos desean escalar, muchos de ellos no consiguen su objetivo, se despeñan y quedan colgando. 
Lo que proponemos es recortar levemente el monto del ingreso básico: en lugar de partir de 1.600 euros al mes, ofreceríamos 1.100 euros a quien no trabaja. Pero también proponemos ser generosos en la fase introductoria: permitir que se pueda ganar hasta 500 euros al mes sin rebajar en nada los subsidios. Esta modificación está en el Gráfico № 15. Y luego, obviamente, tiene que venir una fase en que tendremos que retirar el subsidio a medida que la persona gane más por su cuenta. Admito que en esta fase vuelve a aparecer una pendiente muy pronunciada, que no nos gusta. Podríamos comenzar más hacia la izquierda para suavizarla, pero no sería aceptable políticamente. Con todo, la reforma propuesta hace que la montaña sea menos escarpada que antes, y que sea más probable escalarla.

Si dentro de nuestro esquema alguien decide trabajar media jornada, entonces recibiría una cantidad muy similar a la que obtiene actualmente. Si trabaja más de media jornada, su situación mejorará en términos estrictos. Por ejemplo, al trabajar en jornada completa con el salario más bajo, el monto que obtendríamos en el futuro, con los reajustes salariales, sería mayor que la suma actual. En consecuencia, estamos hablando de una estrategia destinada a aumentar los salarios en el extremo inferior de la distribución de ingresos, cualquiera sea la jornada laboral. Y por supuesto aquellos que no encuentren empleo siempre tendrán la oportunidad de decir: "Quiero permanecer en esta etapa, trabajar para el municipio y hacer valer mi derecho a un contrato de trabajo a plazo fijo, con suministro a terceros". Se trata de un sistema absolutamente seguro al cual tendrían acceso todos los trabajadores, ninguno de los cuales recibirá un ingreso inferior al actual si está dispuesto a trabajar. También es de esperar que una vez que esas personas pasen a tener un empleo estable, desarrollen sus aptitudes y mejoren su actitud hacia el trabajo, y que en el futuro escalen la montaña.

$\mathrm{El}$ hecho de mantener a estas personas ociosas supone un problema social de grandes dimensiones, pues se las aísla de la sociedad. Con ello creamos una subclase con la cual no sabremos cómo lidiar en el futuro. Nuestra propuesta permite evitar esta situación, pues todos están integrados, todos forman parte de la red de relaciones sociales del mundo del trabajo. También se eleva la producción, pues incluso en el caso de aquellos que consiguen empleos de baja productividad, ésta no será igual a cero: ellos producen algo de valor positivo, con lo cual aumenta el PIB. Espero que gracias a este nuevo esquema sea posible escalar la montaña.

Según el modelo que diseñamos para realizar los cálculos, nuestra propuesta crearía más de tres millones de empleos, aún en el caso pesimista donde la elasticidad de demanda laboral es muy baja. Esto es muy significativo. 
GRÁFICO No 15: ASISTENCIA SOCIAL ACTIVADORA

(Para una familia con dos hijos. Considera: ingreso laboral mensual, subsidio de cesantía nivel II, asignación familiar, bono por hijo, impuesto al salario y cotización del trabajador a la seguridad social.)
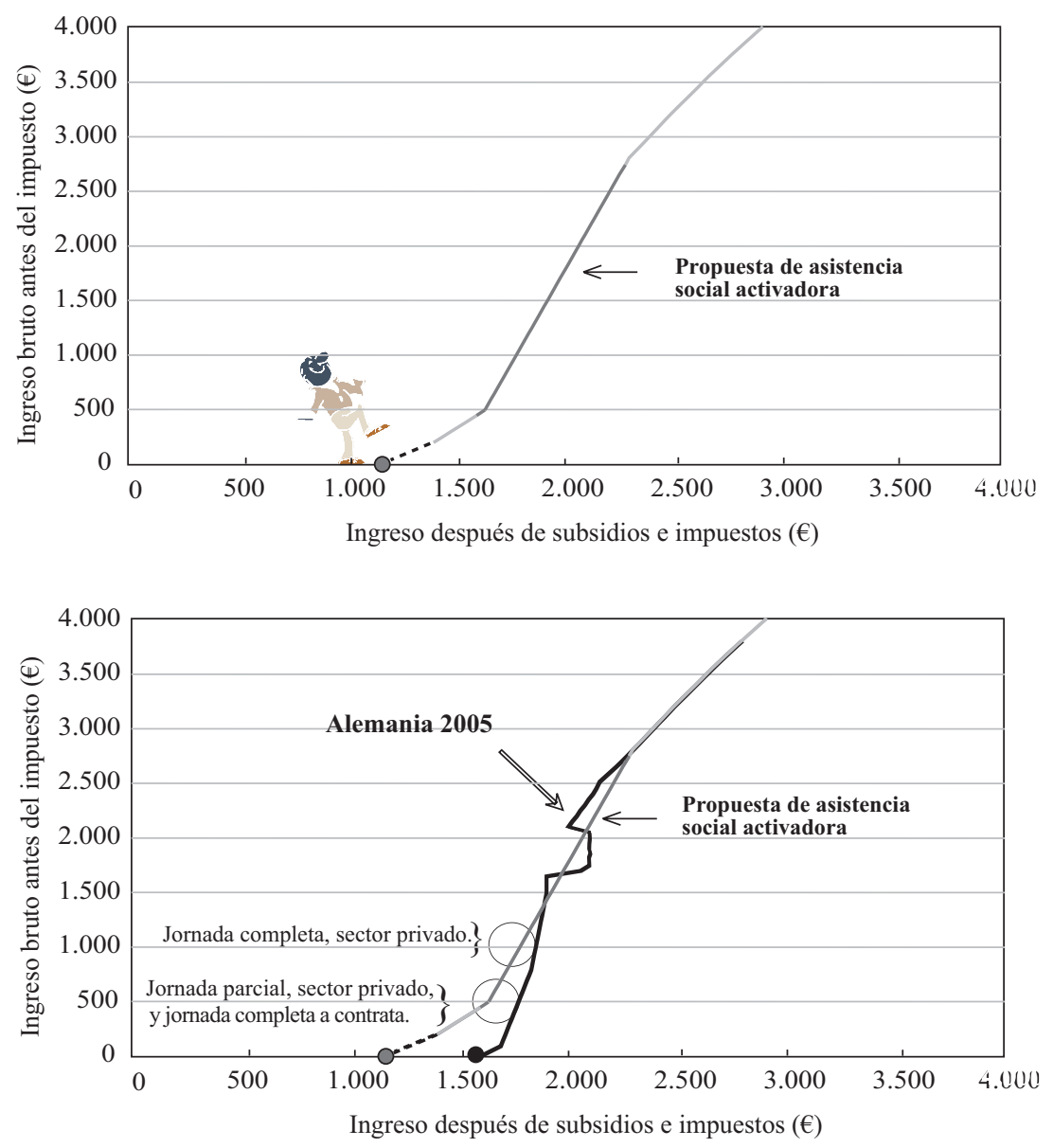

Fuente: Cálculos del Instituto Ifo.

Un aspecto secundario, al cual no nos habíamos referido, que colabora a este resultado, es que nuestro sistema impediría la "inmigración hacia el desempleo”*. Esto ocurre porque el incremento artificial de los salarios

* Nota del editor: Ver la nota 4, supra, en que se cita un trabajo de H. W. Sinn que explica este tema en detalle. 
causados por el Estado de bienestar atrae una inmigración masiva. Para asegurarse un empleo, los inmigrantes ofrecen sus servicios a un salario levemente inferior al que cobran los habitantes locales de baja calificación. Estos últimos, a su vez, tienen la opción de pasar a sentarse en el cómodo sillón que les ofrece el Estado benefactor por el hecho de ser ciudadanos, lo cual es preferible a entrar en una competencia de bajos salarios con los inmigrantes. Se trata, por tanto, de una inmigración "de reemplazo": los habitantes locales se acogen a los subsidios del Estado benefactor, y los inmigrantes ocupan los empleos de baja remuneración en Alemania. Este sistema es desarticulado por nuestra propuesta.

Respecto al costo de administración del esquema que proponemos en el Instituto Ifo, creemos que para el Servicio de Impuestos Internos de Alemania éste sería modesto. Nuestra propuesta es en realidad un impuesto negativo sobre la renta, un esquema permanente que define el ingreso neto para cualquier ingreso bruto, que cubre valores desde cero hasta altos niveles de ingresos.

\section{Comentarios finales}

Alemania ideó el Estado benefactor con las reformas de Bismarck. En ese sentido Alemania fue un conejillo de indias de la Historia, y los demás países pueden ahora apreciar qué aspectos dieron resultado y cuáles no funcionaron. Vuelvo a recalcar que muchas de estas iniciativas sí surtieron efectos positivos: tenemos una sociedad estable, sin delincuencia; tenemos cohesión social. Todos éstos son valores importantes, y por tanto insisto en que el Estado benefactor es un sistema necesario para lograr construir una sociedad moderna.

Sin embargo, también tenemos el lado negativo: esta enorme tasa de desempleo entre los trabajadores no calificados, producto de la compresión artificial de la distribución salarial. Alemania tiene el récord mundial en esta materia. La unificación alemana fracasó en términos económicos precisamente porque el Estado benefactor occidental fue transplantado a Alemania Oriental con toda su generosidad. ¿Pueden imaginarse que el país con los salarios más altos del mundo, y por tanto con los ingresos de reemplazo más altos del mundo, haya puesto en práctica su sistema de ingreso de reemplazo en un país comunista? La iniciativa fue un desastre desde el comienzo. Era imposible que funcionara.

Nuestra solución consiste en introducir una asistencia social activadora: ingreso mínimo en lugar de salario mínimo. Las reformas de Schröder demostraron que ello no es mera teoría sino que da resultado en la práctica. 
Por primera vez en 35 años, desde las reformas sociales introducidas por Willy Brandt a comienzos de los años setenta, Alemania ha conseguido abandonar la senda del desempleo galopante, porque Schröder adoptó una vía más orientada hacia el mercado, pagando menos dinero por estar inactivo y más por trabajar. Esa estrategia ha permitido ampliar la distribución salarial y crear empleos en Alemania. 